\title{
BMJ Open Temporal trends of carbon monoxide poisoning mortality at the global, regional and national levels: a cross- sectional study from the Global Burden of Disease study, 1990 and 2017
}

\author{
Jianhai Long, ${ }^{1}$ Yawei Sun, ${ }^{2}$ Junxiu Zhao, ${ }^{2}$ Jie Liu, ${ }^{3}$ Xiaobo Peng (1) ${ }^{2}$
}

To cite: Long J, Sun Y, Zhao J, et al. Temporal trends of carbon monoxide poisoning mortality at the global, regiona and national levels: a crosssectional study from the Global Burden of Disease study, 1990 and 2017. BMJ Open 2021;11:e053240. doi:10.1136/ bmjopen-2021-053240

- Prepublication history and additional supplemental material for this paper are available online. To view these files, please visit the journal online (http://dx.doi.org/10.1136/ bmjopen-2021-053240)

$\mathrm{JL}$ and $\mathrm{YS}$ are joint first authors.

Received 14 May 2021 Accepted 22 October 2021

Check for updates

(c) Author(s) (or their employer(s)) 2021. Re-use permitted under CC BY-NC. No commercial re-use. See rights and permissions. Published by BMJ.

For numbered affiliations see end of article.

Correspondence to Dr Xiaobo Peng; xiaobopeng911@163.com and Dr Jie Liu;

braindream@163.com

\section{ABSTRACT}

Objectives Carbon monoxide (CO) poisoning is one of the most frequent causes of fatal poisoning worldwide. Few studies have explored the mortality trends of $\mathrm{CO}$ poisoning grouped by age and gender, at the regional, national and global levels. We therefore aimed to determine the pattern of $\mathrm{CO}$ poisoning mortality, as well as temporal trends at all levels.

Design A cross-sectional survey design was used in this study.

Setting CO poisoning data collected from the Global Burden of Diseases (GBDs), from 1990 to 2017, was arranged by sex, age, region and country. In addition, we used human development index data at the national level from the World Bank.

Participants We collected over 100000 information on CO poisoning mortality between 1990 and 2017, derived from the GBD study in 2017.

Main outcomes and measures We have calculated the estimated annual percentage changes in $\mathrm{CO}$ poisoning age-standardised mortality rate (ASR), by sex and age at different regions and countries to quantify the temporal trends in CO poisoning ASR.

Results Globally, death cases of CO poisoning decreased $7.2 \%$ from 38210 in 1990 to 35480 in 2017. The overall ASR decreased by an average of $1.83 \%$ (95\% Cl $2.10 \%$ to $1.56 \%$ ) per year in this period. This decreasing pattern was heterogeneous across ages, regions and countries. The most pronounced decreases were generally observed in countries with a high sociodemographic index, including Estonia, South Korea and Puerto Rico.

Conclusions Current prevention strategies should be reoriented, and much more targeted and specific strategies should be established in some countries to forestall CO poisoning.

\section{INTRODUCTION}

Carbon monoxide (CO) is a colourless, odourless and tasteless non-irritant gas, making it imperceptible to human senses. ${ }^{1}$ Major nonoccupational sources include poorly maintained or ventilated home heating systems, cooking appliances, motor vehicle exhaust and
Strengths and limitations of this study

- Our study is the first to include regional, national and global levels extracted from Global Burden of Disease (GBD) study data.

- We presented temporal trends in carbon monoxide (CO) poisoning mortality by age and sex.

- This study analyses the secondary data of the GBD Study and hence it has all the limitations of the data.

- There may be an underestimation of individual CO poisoning aetiologies due to underdeveloped countries having poor quality and completeness of reporting on $\mathrm{CO}$ poisoning.

- This study informs the policymakers on further strategies to control $\mathrm{CO}$ poisoning mortality.

gasoline or other fuel-powered equipment (eg, portable generators and space heaters). ${ }^{2}$ The initial symptoms of $\mathrm{CO}$ poisoning are primarily nausea, fatigue, tachypnoea, headache, confusion and clumsiness, ${ }^{3}$ which are non-clinical effects that often lead to underdiagnosis or misdiagnosis of CO exposure. ${ }^{4}$ Exposure to CO is a serious health concern because individuals can be severely or fatally poisoned before even realising that they have been exposed. ${ }^{1}$

$\mathrm{CO}$ toxicity is one of the most common types of fatal poisoning in many countries. ${ }^{5}$ The underlying causes, prevention and treatment measures for $\mathrm{CO}$ poisoning have been extensively investigated in previous epidemiological studies. ${ }^{26-9} \mathrm{CO}$ poisonings have been attributed to coal stoves used for heating, shower system water heaters, house or building fires, indoor charcoal barbecue use, disasters (eg, improper use of generators and charcoal grills after disasters, such as hurricanes ${ }^{10}$ ), exposure to exhaust during recreational boating, ${ }^{7}$ automobile exhaust gas and recreational boaters. ${ }^{8}$ Most incidents have occurred in residential settings. ${ }^{11}$ Reduced release of $\mathrm{CO}$ can be 
achieved through engineering innovations, ${ }^{12}$ such as the installation of catalytic converters in motor vehicles ${ }^{13}$ and the replacement of coal gas with natural gas. ${ }^{14-16}$ The installation of $\mathrm{CO}$ alarms can help prevent CO exposure, ${ }^{12} 1718$ as well as appropriate public education. ${ }^{19}$ There are also several measures available to treat $\mathrm{CO}$ poisonings, such as hyperbaric oxygen therapy ${ }^{20}$ and advanced life support. ${ }^{21}$ Consequently, most countries have observed a decreasing $\mathrm{CO}$ poisoning mortality trend, for example in the USA ${ }^{22}$ and England. ${ }^{23}{ }^{24}$ In contrast, a few countries, such as Iran ${ }^{23}$ and Belarus ${ }^{25}$ showed a stable and an increasing trend, respectively. Therefore, we hypothesised that the temporal trends of carbon monoxide poisoning mortality could be related to geography and economics ${ }^{26}$ at regional, national, and global levels.

The Global Burden of Disease (GBD) study assessed the CO poisoning burden in 195 countries and territories and provided a unique opportunity to understand its landscape. ${ }^{27}$ In the current study, we retrieved detailed information on $\mathrm{CO}$ poisoning mortality grouped by age and sex from the GBD study 2017. We further assessed the disease burden of $\mathrm{CO}$ poisoning by determining temporal trends of CO poisoning mortality from 1990 to 2017 at regional, national and global levels and in relation to human characteristics. Our results can assist in the design of targeted strategies for $\mathrm{CO}$ poisoning prevention tailored to different countries.

\section{MATERIALS AND METHODS}

\section{Study data}

Annual deaths and age-standardised mortality rates (ASRs) for CO poisoning from 1990 to 2017 grouped by sex, age, region and country were collected from the GBD using the Global Health Data Exchange query tool (http://ghdx.healthdata.org/gbd-results-tool). ${ }^{27}$ The study design, metrics and analysis were published elsewhere..$^{28}$ The CO poisoning mortality GBD $2017^{28}$ study used data from over 100000 sources covering the years between 1990 and 2017.

Annual cases and age-standardised incidence rates for CO poisoning from 1990 to 2017 remain stable as online resource $1 \mathrm{a}$ in online supplemental file. ${ }^{28}$ According to sociodemographic index (SDI) data (online supplemental online resource $1 \mathrm{~b}$ in online supplemental file), ${ }^{29}$ the 195 countries and territories in the GBD $2017^{28}$ data were divided into five groups: low, low-middle, middle, highmiddle and high SDI; and into 21 regions (online resource $1 \mathrm{~b}$ in online supplemental file) $)^{30}$ according to their geographical location, such as East Asia, Central Europe, High-income North America, Oceania and Eastern SubSaharan Africa. The methods for GBD data extraction and disease burden estimation were based on Liu $e t a l .{ }^{31}$ Moreover, we collected and analysed the human development index (HDI) (online resource $1 \mathrm{~b}$ in online supplemental file $)^{32}$ and matched it with GBD data.

This study used the data freely available from the Institute for Health Metrics and Evaluation (IHME)'s
GBD database. Patients were not involved in the design, recruitment or conduct of the study.

\section{Statistical analysis}

We quantified $\mathrm{CO}$ poisoning death rate changes by estimating the annual percentage change (EAPC) from the ASRs. ${ }^{33}$ ASR trends can serve as a suitable surrogate for shifting patterns of disease within a population and providing insights into changing causal factors. The calculation methods for ASR and EAPC are given as below, according to Liu et al. $^{31}$ ASR was considered increased when the $\mathrm{EAPC}^{34}{ }^{35}$ value and its lower $95 \%$ CI boundary were $>0$, decreased when the EAPC value and its upper 95\% CI boundary were both $<0$ and remained constant when the $95 \%$ CI of the EAPC value was 0 . Additionally, to explore the factors influencing EAPC, we assessed the associations between EAPC and each ASR (1990) and HDI (2017) with quadratic prediction plots at the national level. Then, three groups of countries were selected for comparison from inside and outside the CI of the quadratic prediction plots. All data were analysed using the R software (V.3.5.1, Institute for Statistics and Mathematics) and STATA/MP (STATA V.13.1, Stata Corp). A p value $<0.05$ was considered statistically significant.

ASR was defined as (per 100000 population) following the direct method calculated by ${ }^{36}$ :

$$
\mathrm{ASR}=\frac{\sum_{i=1}^{A} a_{i} w_{i}}{\sum_{i=1}^{A} w_{i}} \times 100000
$$

where summing up the products of the age-specific rates $\left(\alpha_{i}\right.$, where $i$ denotes the $i$ th age class) and the number of persons (or weight) $\left(\omega_{i}\right)$ in the same age subgroup $i$ of the chosen reference standard population, then dividing the sum of standard population weights.

The EAPC was defined by a summary and widely used measure of the ASR trend over a specified interval. ${ }^{37} \mathrm{~A}$ regression line was fitted to the natural logarithm of the rates:

$$
y=\alpha+\beta x+\varepsilon
$$

where $y=\ln (\mathrm{ASR})$ and $x=$ calendar year. The EAPC was calculated as $\mathrm{EAPC}=\left(e^{b}-1\right) \times 100$ and its $95 \%$ CI can also be obtained from the linear regression model.

The HDI was defined as a composite index measuring average achievement in three basic dimensions of human development: a long and healthy life, knowledge and a decent standard of living. See Technical note $1^{32}$ at http://hdr.undp.org/sites/default/files/hdr2018_technical_notes.pdf for details on how the HDI is calculated.

The SDI was defined using log lag dependent income per capita, average educational attainment in the population over age 15 , and total fertility rate. For detailed data of SDI and HDI see online supplemental table 1.

\section{RESULTS}

\section{Global CO poisoning burden}

Table 1 shows the deaths and ASRs following CO poisoning from 1990 to 2017 and the changes that have 
A

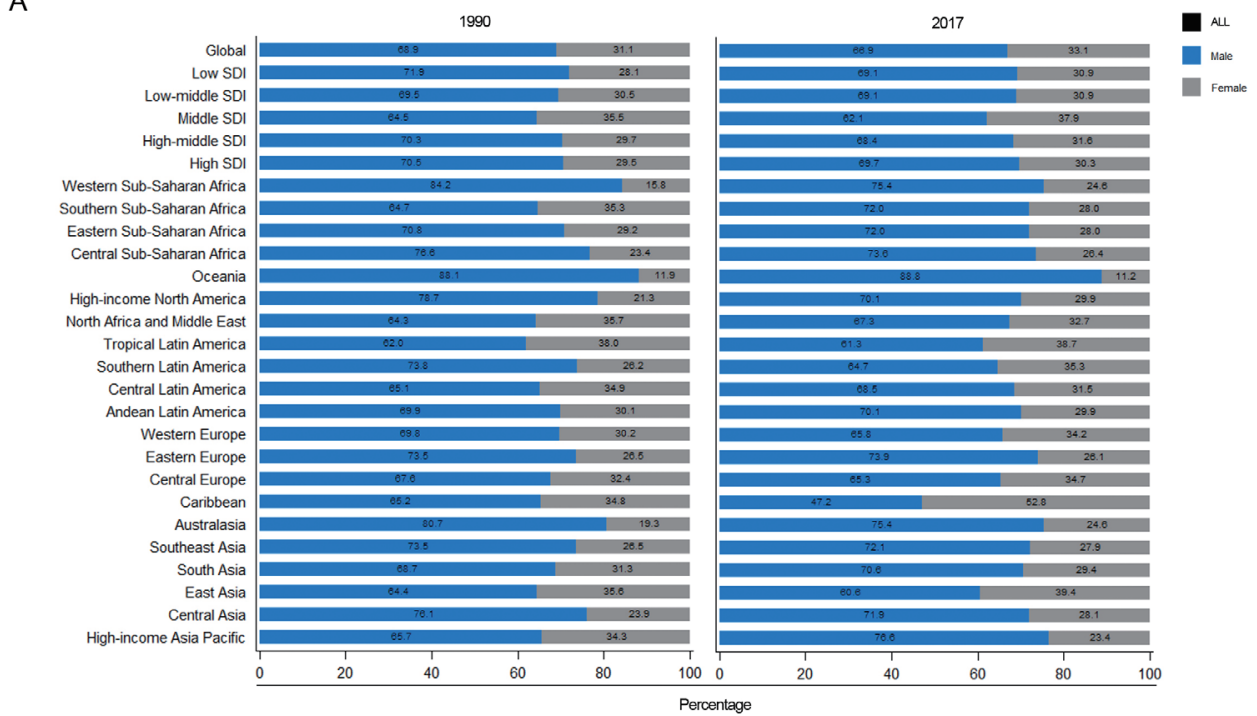

B

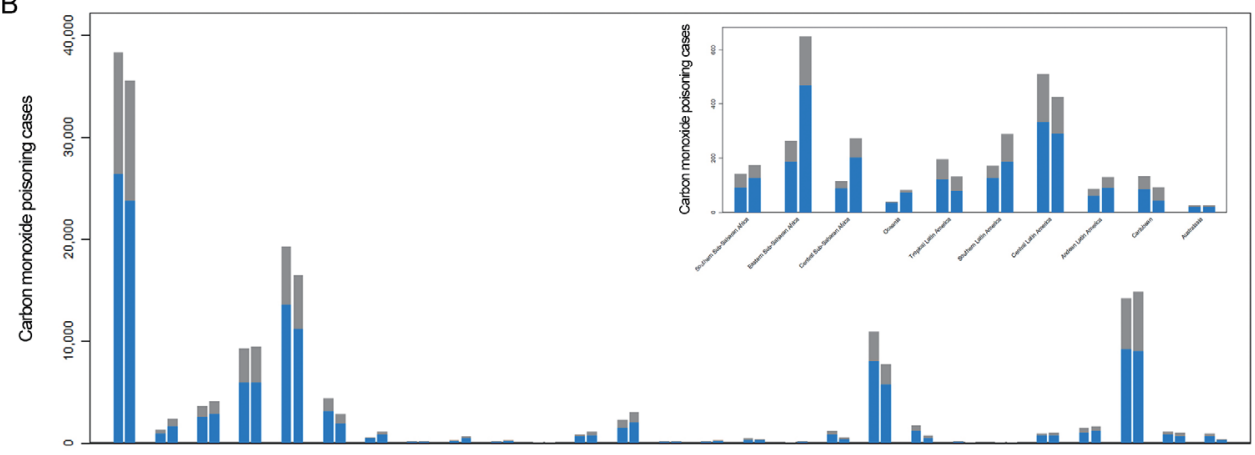

C

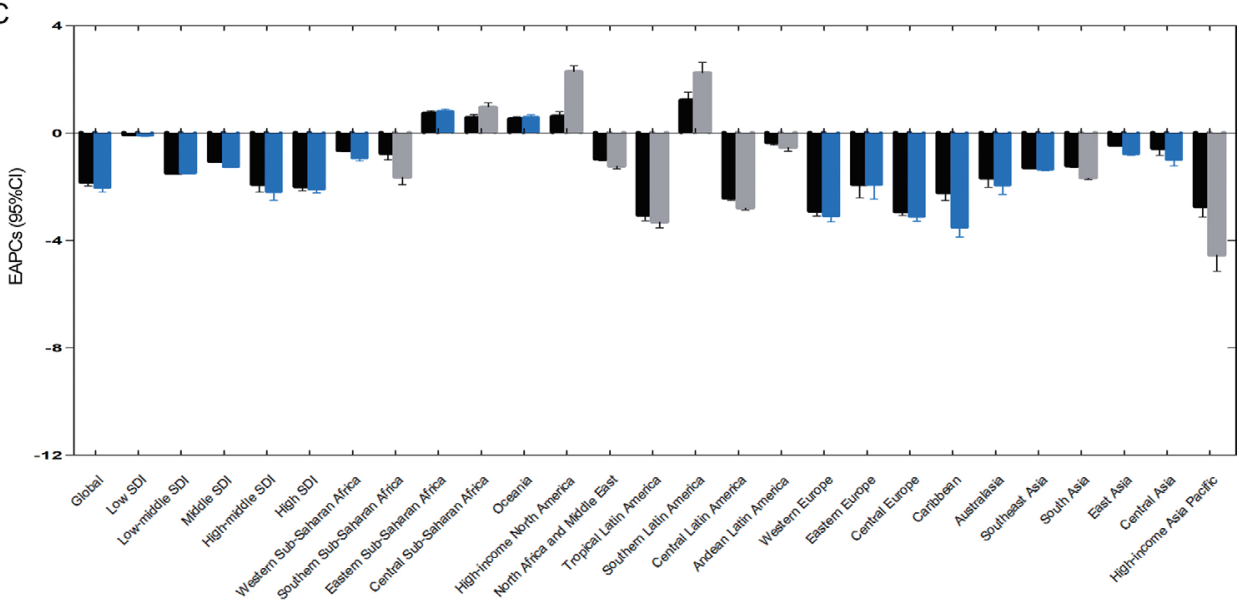

Figure 1 Carbon monoxide (CO) poisoning mortality grouped by region and sex. (A) Proportion of CO poisoning deaths for each sex by region, in 1990 and 2017. (B) Numbers of CO poisoning deaths; the left column in each pair represents 1990 data and the right column 2017 data; the inset shows regions with low case report numbers reproduced at a different scale for clarity. (C) The estimated annual percentage change (EAPC) in the CO poisoning age-standardised mortality rate from 1990 to 2017 , showing the EAPC for all cases and the larger of the sex changes for each region.

occurred during this period. At a global level, the deaths decreased by $7.12 \%$. The global ASR was 0.71 per 100 000 in 1990 and 0.46 per 100000 in 2017, a decrease of 1.83 per year (95\% CI 2.10 to 1.56 ) (table 1 ). Between the sexes, male mortality was higher at 26320 deaths $(68.9 \%)$ in 1990 and 23730 (66.9\%) in 2017 (figure 1A,B and table 1). The ASR decreased in both sexes, especially in males, for whom the EAPC was -2.02 (95\% CI -2.35 to -1.70 ) (figure $1 \mathrm{C}$ and table 1 ). Across the age groups, the most deaths occurred between 15 and 49 years in 18 260 patients $(47.8 \%)$ in 1990 and 14630 patients $(41.2 \%)$ in 2017 (figure 2A,B and table 1). As figure 2 shows, the proportion of deaths among individuals aged $<50$ years has decreased, whereas that among those aged $>50$ years has increased. Additionally, the ASR decreased in all age groups, except the $>70$-year group; children under 5 years 
A

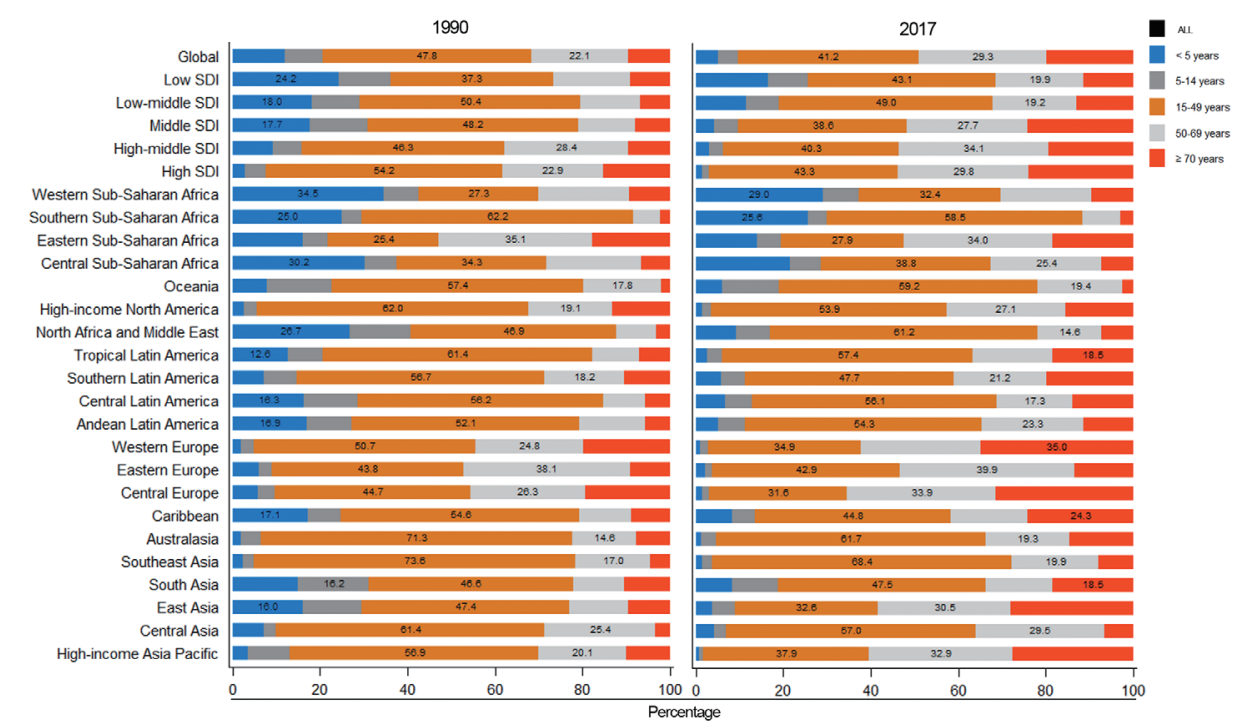

$\mathrm{B}$

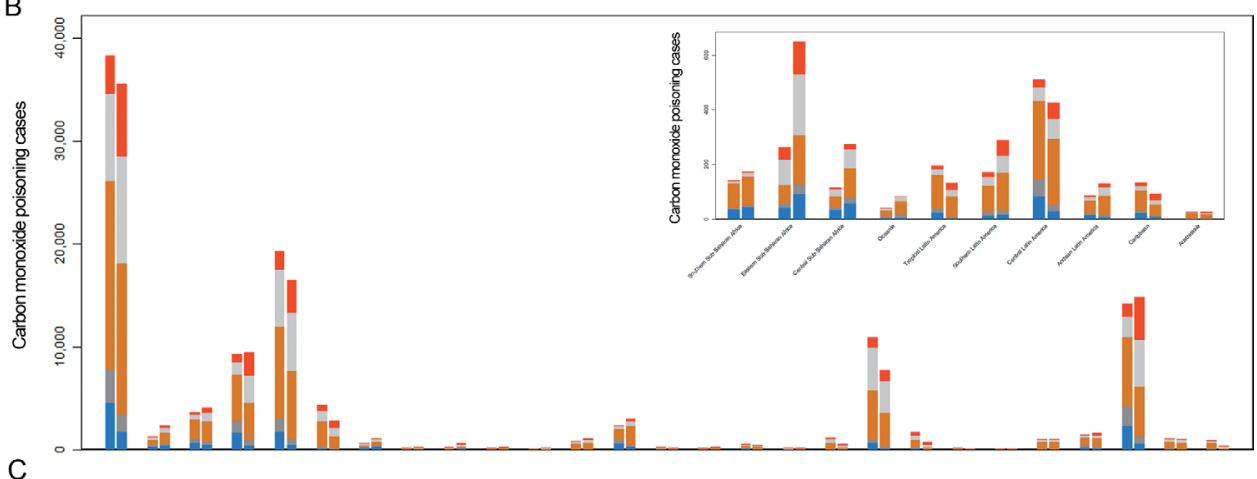

$\mathrm{C}$

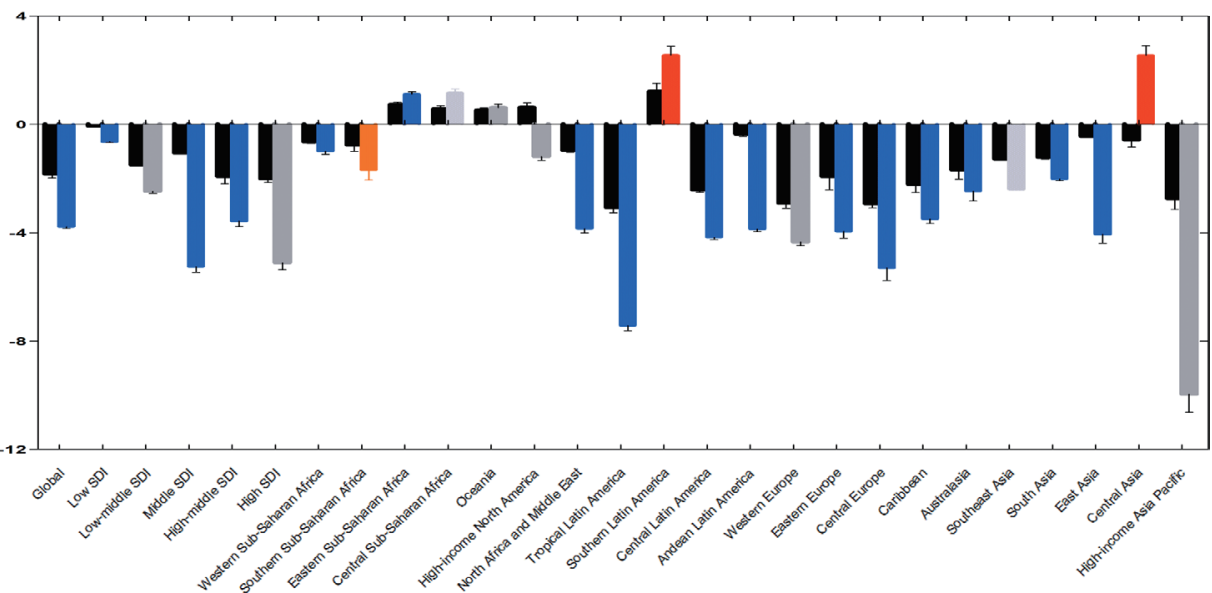

Figure 2 Carbon monoxide (CO) poisoning mortality grouped by region and age. (A) Proportion of $\mathrm{CO}$ poisoning deaths in 1990 and 2017. (B) Numbers of CO poisoning deaths in 1990 and 2017; the left column in each pair represents 1990 data and the right column 2017 data; the inset shows regions with low case report numbers reproduced at a different scale for clarity. (C) The estimated annual percentage change (EAPC) in the CO poisoning age-standardised mortality rate from 1990 to 2017, showing the EAPC for all cases and the largest of the age group changes for each region.

experienced the largest decrease in EAPC of $3.77(95 \%$ CI 3.90 to 3.64) (figure $2 \mathrm{C}$ and table 1 ).

\section{Regional CO poisoning burden}

Table 1, figures 1 and 2 show the changes in deaths and ASRs due to CO poisoning between 1990 and 2017, grouped by sex and age and categorised by SDI level and geographical regions, respectively. Concerning SDI, deaths due to $\mathrm{CO}$ poisoning increased in areas with low, low-middle and middle scores and decreased in areas with high-middle and high scores. Surprisingly, the ASR decreased at all five SDI levels, especially in the areas with high SDI scores, which had an EAPC of $-2.00(95 \%$ CI -2.28 to -1.71 ) (table 1 ). In terms of sex, similar to the global trend, more than half of the patients with 
$\mathrm{CO}$ poisoning weremale. Moreover, the ASR decreased for male at all five SDI levels (figure 1A-C and online resource 2 in online supplemental file). Regarding age, the difference in proportion of deaths between 1990 and 2017 is that the second-highest proportion of deaths occurred in the <5-year group in 1990 and in the 50 to 69-year group in 2017 in low-scoring, low-middle-scoring and middle-scoring SDI regions, others producing the same distribution change as that seen globally (figure 2A and online resource 2 in online supplemental file). The ASR in regions with low, middle and high-middle SDI scores decreased the most in the $<5$-year group, with EAPCs of -0.63 (95\% CI -0.70 to -0.57$),-5.25$ (95\% CI -5.64 to -4.85 ) and -3.57 (95\% CI -3.94 to -3.20$)$, respectively. The largest ASR decrease in regions with lowmiddle and high SDI scores was in those aged 5-14 years (figure 2C and online resource 2 in online supplemental file). Surprisingly, contrary to global trends, deaths in the groups aged 50-69 and $>70$ years increased in regions with middle SDI scores, with EAPCs of $0.36(95 \%$ CI 0.07 to 0.66 ) and 1.21 (95\% CI 0.85 to 1.56 ), respectively (online resource 2 in online supplemental file).

Geographical regions varied, with numbers of deaths in 2017 being higher in 11 regions, lower in 9 regions and stable in 1 region compared with those in 1990. The ASR decreased in 17 regions, increased in 3 regions and was stable in 1 region in the same comparison. Eastern Europe had the highest ASR in 2017, followed by Central Asia and East Asia. Sixteen of the 21 geographical regions demonstrated a negative EAPC; the greatest decrease was found in Tropical Latin America, with an EAPC of -3.06 (95\% CI -3.44 to -2.68), followed by that in Central Europe. In contrast, the greatest ASR increase was found in Southern Latin America, with an EAPC of 1.23 (95\% CI 0.67 to 1.80 ) (table 1). Sex analysis showed that male deaths comprised approximately $60 \%$ in 19 of the 21 geographical regions, except in Oceania $(88.8 \%)$ and the Caribbean (only 47.2\%) (figure 1A). In the 16 regions with a negative EAPC, 9 showed a more pronounced change for men; of the other 5 regions, 2 showed this pattern. In Oceania, males with EAPC of 0.60 (95\% CI 0.43 to 0.76 ) showed that male ASR increased more than female (EAPC of $0.13,95 \%$ CI 0.05 to 0.21 ), whereas in the Caribbean, males with EAPC of -3.51 (95\% CI -4.20 to -2.82 ) showed that male ASR decreased much more than female (EAPC of $-0.60,95 \%$ CI -0.94 to -0.25 ) (figure 1C). Across the age groups, some regions differed from the global distribution, in which more than half of deaths were among those aged 15-69 years. In Western and Southern sub-Saharan Africa, the largest proportions of deaths occurred among those aged 15-49 and $<5$ years, respectively; in South Asia, the Caribbean, Western Europe and Tropical Latin America, deaths were the highest among those aged 15-49 and $>70$ years (figure 2A). Twelve regions had their greatest absolute EAPC among those aged $<5$ years, four among those aged $5-14$ years, one among those aged $15-49$ years, two among those aged 50-69 years and two aged $>70$ years.
Two of these regions show the opposite. The high-income North American increased in ASR, while the pronounced change in the 50 to 69-year-old group with EAPC of -1.19 (95\% CI -1.46 to -0.91$)$. Central Asia's ASR decreased, while the pronounced one is $>70$-year-old group with EAPC of 2.55 (95\% CI 1.84 to 3.26) (figure 2C and online resource 2 in online supplemental file).

\section{National CO poisoning burden}

Figures 3 and 4 and online resources 3-13 in online supplemental file show changes in deaths and agestandardised mortality due to CO poisoning from 1990 to 2017 according to sex and age at the national level. China had the largest number of $\mathrm{CO}$ poisoning-related deaths in both 1990 (13 779) and 2017 (14 255), although the growth rate was only $3.46 \%$ (online resource 3 in online supplemental file). The UAE had the largest increase, with a growth rate of $625.26 \%$. In contrast, Finland had the largest decrease, a reduction of $95.31 \%$ (figure 3B and online resource 3 in online supplemental file). The ASR varied greatly from country to country. Moldova had the highest ASR, at 4.68 per 100000 in 2017, followed by the Russian Federation and Lithuania (figure 3A). The highest ASR in 1990 was also observed in the Russian Federation. The largest decrease in ASR was found in Estonia, at 9.76 per year (95\% CI -10.43 to -9.08 ), followed by South Korea and Puerto Rico. In contrast, Mauritius had a substantial ASR increase of 6.27 per year (95\% CI 4.75 to 7.82 ) (figure 3C and online resource 3 in online supplemental file). Of the 195 countries and territories, 129 demonstrated a decrease, 49 an increase and 17 a constant trend in ASR from 1990 to 2017 (online resource 3 in online supplemental file). For sex, most trends were consistent with those at the national level. Moldova had the highest ASR at 2.47 per 100000 in females and 7.10 per 100000 in males (online resources 4, 7A and 8A in online supplemental file). Bangladesh and the UAE had the largest increase in female and male $\mathrm{CO}$ poisoning-related deaths, respectively (online resources $4,7 \mathrm{~B}$ and $8 \mathrm{~B}$ in online supplemental file). The highest EAPC for females was found in Thailand, at 7.93 (95\% CI 6.73 to 9.15). In contrast, the lowest EAPC for females was observed in South Korea, at -8.80 (95\% CI -10.41 to -7.13 ) (online resources 4 and $7 \mathrm{C}$ in online supplemental file). Moldova had the largest ASR increase for males, and Finland had the largest decrease (online resources 4 and $8 \mathrm{C}$ in online supplemental file). Considering age, most trends were again consistent with those at the national level. Moldova had the highest ASR in $<5$ years (1.82 per 100000$), 5-14$ years (526.34\%), 15-49 years, $50-70$ years $(8.19$ per 100000$)$ and $>70$ years $(12.86$ per 100000 ). Russia had the highest ASR in 5-14 years (0.66 per 100000$)$ and $15-49$ years (3.56 per 100000$)$ (online resources 5, 9A, 10A, 11A, 12A and 13A in online supplemental file). Thailand, Bangladesh and Turkey had the largest increase in deaths among individuals aged $<5$ years $(306.95 \%), 5-14$ years $(526.34 \%)$ and $>70$ years $(532.83 \%)$, respectively. In contrast, Estonia and 


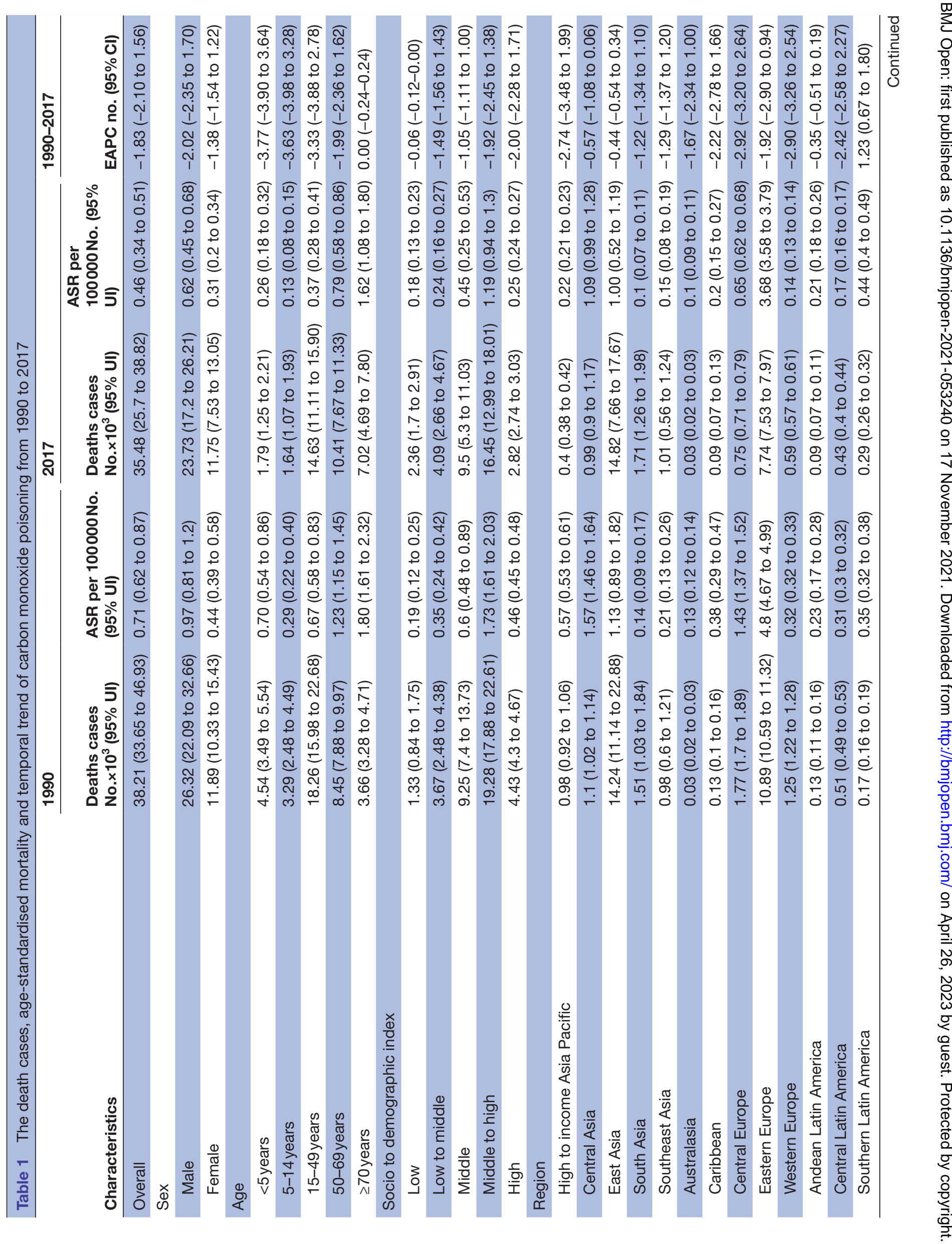


South Korea reported the greatest decrease among individuals aged $<5$ years and $5-14$ years, respectively (online resources 5. 9B, 10B, 11B, 12B and 13B in online supplemental file). South Korea also reported the lowest EAPCs among individuals aged $<5$ years and $15-49$ years; in addition, Bermuda observed this change in those aged 5-14 years. In contrast, the largest EAPCs were observed among individuals aged $5-14$ and $>70$ years in Kazakhstan and 15-49 years in Thailand (online resources 5, 9C, 10C, $11 \mathrm{C}, 12 \mathrm{C}$ and $13 \mathrm{C}$ in online supplemental file).

As shown in figure 4, ASR (in 1990) and HDI (in 2017) were significantly associated with EAPC. The ASR related to $\mathrm{CO}$ poisoning in 1990 reflects the $\mathrm{CO}$ poisoning at baseline, and the HDI in 2017 can serve as a surrogate for the level and availability of healthcare in each country. A significant negative association was found between EAPC and ASR $(r=-0.365, p<0.001)$ when the ASR was limited to less than 2.816 per 100 000. In contrast, when the ASR was above 2.816 per 100000 , the association disappeared, such as in Moldova, Estonia and Finland (online resource 6 in online supplemental file). Additionally, a significant negative relationship was detected between EAPC and HDI $(r=-0.356, p<0.001)$. Countries with a higher HDI have experienced a more rapid decrease in their $\mathrm{CO}$ poisoning ASRs between 1990 and 2017.

\section{DISCUSSION}

$\mathrm{CO}$ poisoning is one of the most common types of fatal poisoning worldwide. ${ }^{312}$ In the current study, we comprehensively analysed temporal changes in $\mathrm{CO}$ poisoning deaths grouped by age and sex at, regional, national and global levels. In general, CO poisoning mortality reduced between 1990 and $2017 .{ }^{38}$ A sex-based disparity was present, with male ASR and deaths being almost twice as high as females. ${ }^{11}{ }^{12}$ Males may experience greater $\mathrm{CO}$ exposure as they more frequently use CO-emitting equipment, ${ }^{12} 39$ causing higher mortality. ${ }^{711}$ Additionally, females have an advantage over males in terms of the severity of poisoning and subsequent prognosis; they may be more likely to visit the emergency department earlier (and thus receive treatment that prevents death) and manifest symptoms of $\mathrm{CO}$ poisoning earlier due to their smaller size and lower red blood cell count. ${ }^{2}$ Across age groups, the largest percentage of global $\mathrm{CO}$ poisoning deaths occurred among those aged 15-49 years; the percentage of such deaths decreased in the $<50$-year group and increased in the $>50$-year group, which is related to ageing populations. ${ }^{40}$ The highest $\mathrm{CO}$ poisoning ASRs were seen among individuals aged $>70$ years. ${ }^{3}$ Elderly people may have comorbidities with cardiopulmonary disease ${ }^{41}$ and can easily be misdiagnosed ${ }^{42}$ which leads to higher hospitalisation $^{2}$ and death rates in this population. ${ }^{43}$ However, the heterogeneous pattern observed across region, nation and population characteristics results in markedly diverse $\mathrm{CO}$ poisoning mortalities globally and makes the prevention of CO poisoning complex. ${ }^{26}$ For example, the increasing ASR in Southern Latin America is most 


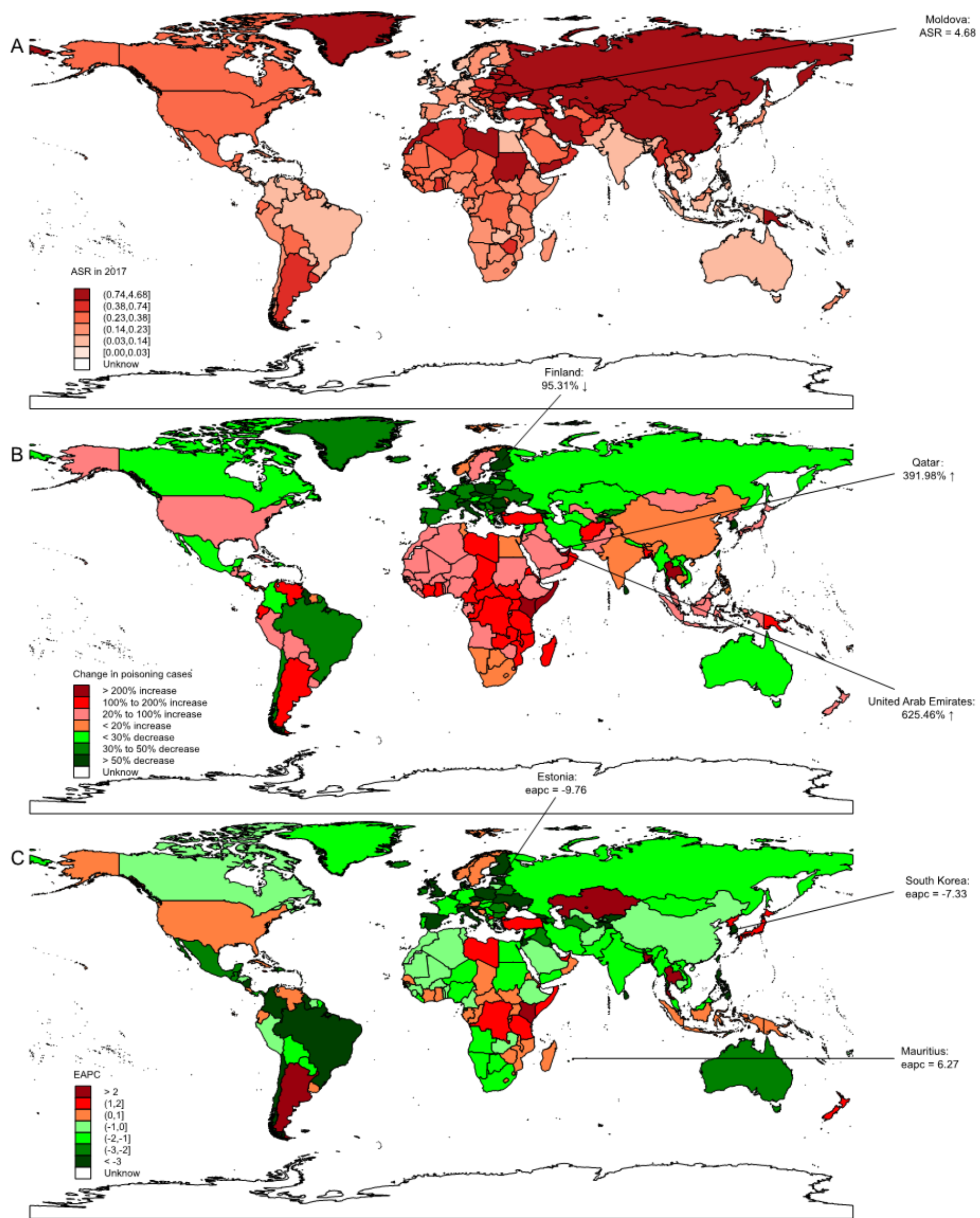

Figure 3 The global disease burden of carbon monoxide (CO) poisoning in 195 countries and territories. (A) The agestandardised mortality rate (ASR) for CO poisoning in 2017. (B) The percentage change in CO poisoning deaths between 1990 and 2017. (C) The estimated annual percentage change (EAPC) in the CO poisoning ASR from 1990 to 2017. 
A

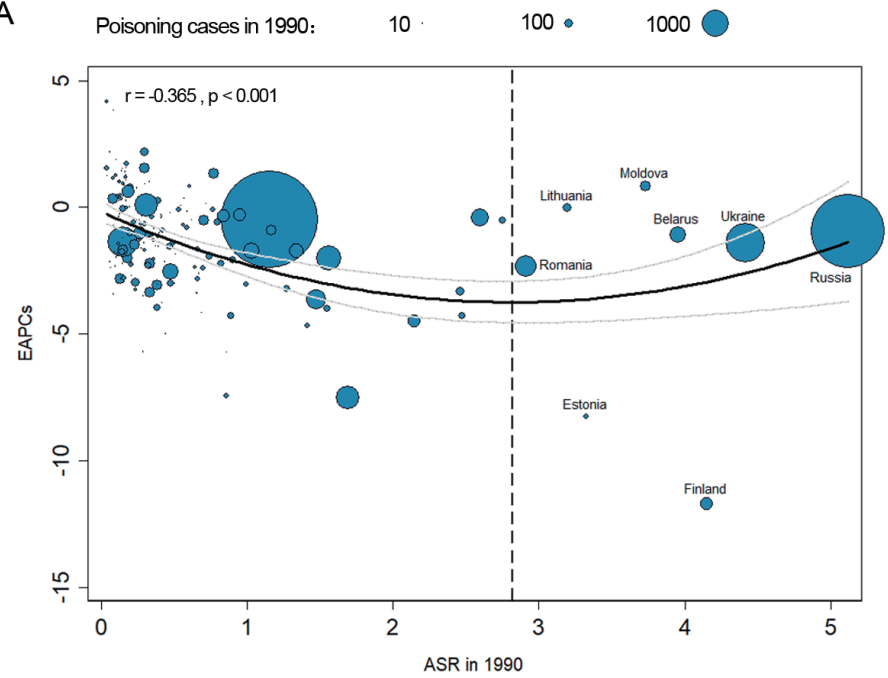

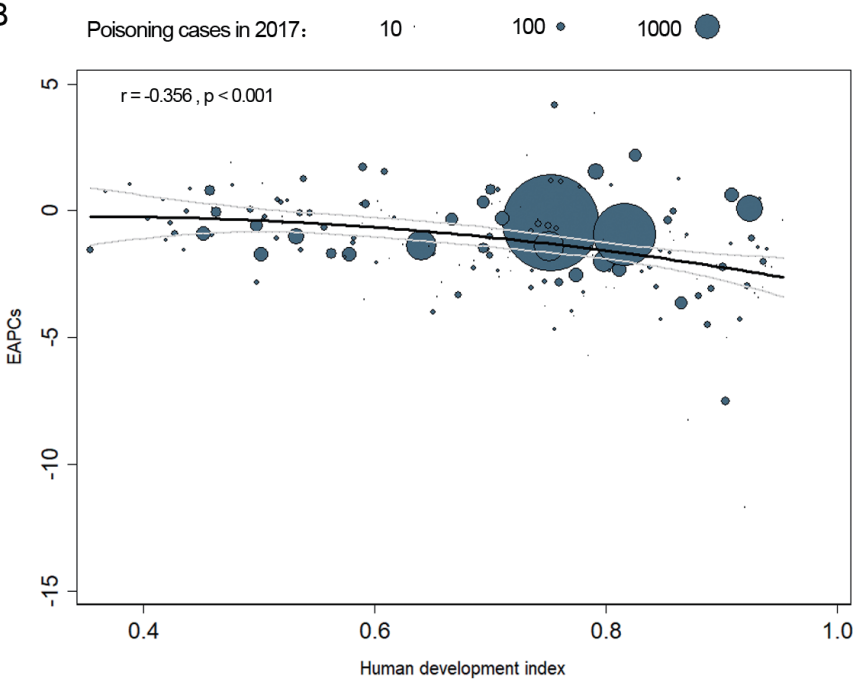

Figure 4 Correlations between estimated annual percentage change (EAPC) and (A) the carbon monoxide (CO) poisoning agestandardised mortality rate (ASR) in 1990, and (B) human development index (HDI) in 2017; the circles represent countries with available HDI data, and their size indicates the number of death cases.

pronounced, as measured by EAPC, among females and those aged $>70$ years. This is quite unlike the situation in the Caribbean, which has a decreasing ASR that is most pronounced in males and those $<5$ years old.

\section{Regional differences in $\mathrm{CO}$ poisoning mortality distribution}

Economics and geography determine individual susceptibility to CO poisoning. ${ }^{26}$ EAPC values tended to decrease with increasing SDI scores. This implies that a high value of SDI, which combines low-rate total fertility, average to high educational attainment in the population over age $15,{ }^{44}$ and high income per capita, ${ }^{17} 23$ could reduce CO poisoning fatalities. $\mathrm{CO}$ poisoning has been reported to be the most frequent cause of fatal poisoning in children, infants and fetuses, ${ }^{3}$ which may explain reductions in ASR consequent on low-rate total fertility. Considering geographical regions, the CO poisoning ASRs in Central and Eastern Sub-Saharan Africa, Southern Latin America, and high-income North America demonstrated an increasing trend. In contrast, a decline in ASR was present in the remaining 16 regions, such as Tropical Latin America, Europe and the Caribbean. Most regions with ASR increases ${ }^{38}$ were located between $40^{\circ} \mathrm{S}$ and $40^{\circ} \mathrm{N}$, which have more than half of the countries with low to middle SDI scores, indicating low economic and healthcare levels. ${ }^{45}$

\section{National differences in $\mathrm{CO}$ poisoning mortality distribution}

The level of CO exposure is closely related to socioeconomic status, education, medical level and national policies. HDI and EAPC were found to be negatively correlated, which means that long and healthy life, adequate education, ${ }^{11}$ and a high per capita gross domestic product ${ }^{46}$ induce a decline in ASR. Similarly to SDI scores, the major causes of $\mathrm{CO}$ poisonings consist of non-standardised traditional heating systems commonly used in countries with low socioeconomic status. ${ }^{47}$ Additionally, ASR in 1990 (baseline) had a significant negative association with EAPC when the ASR was limited to below 2.816 per 100000 . This means that the worse the initial $\mathrm{CO}$ poisoning situation, the more impact $\mathrm{CO}$ poisoning prevention measures will have. Three groups of countries were selected for detailed comparison: conforming to the fit curve (USA), higher than the fit curve (Moldova, Lithuania) and lower than the fit curve (Estonia) (online supplemental online resource 6). These four countries showed ageing trends, which did not differ significantly between each other in population proportion, sex ratio and age composition. Interestingly, excluding economic effects, promulgation and compliance with ordinances have become the main factors influencing EAPCs. For example, Estonia had the lowest national EAPC following mandatory fitting of automatic fire alarm systems (smoke alarms) at homes. ${ }^{48}$ Conversely, although some states of the USA have also issued corresponding regulations, only $30 \%-50 \%$ compliance has been observed ${ }^{49}$ because a low initial ASR caused low-risk perception; this resulted in an increasing ASR. Consequently, it is recommended that countries with both high ASR and middle-to-high SDI scores, such as Moldova and Lithuania, issue laws that require the installation of $\mathrm{CO}$ detectors in residences ${ }^{16}$ and enhance education and publicity, which will improve public health ${ }^{49}$ and economic performance. ${ }^{17}$

\section{Differences in population characteristics should also guide prevention measures}

In relation to sex, male deaths in Oceania were exceptionally high $(88.8 \%)$ and in the Caribbean exceptionally low (47.2\%) compared with approximately $60 \%$ in the remaining 19 geographical regions. Development of fishing has a higher risk of $\mathrm{CO}$ fatality largely because of the need for portable heating sources, work in confined spaces (eg, boat cabin, water holding tanks) and remote locations far from medical care, and often solitary work. ${ }^{39}$ Fisheries are a major industry in Oceania, ${ }^{50}$ which leads to 
a fivefold higher mortality rate for men than women. ${ }^{39}$ In contrast, the Caribbean has prospered through tourism, ${ }^{51}$ leading to a huge drop in male mortality. Consequently, it is important to reduce the mortality of $\mathrm{CO}$ poisoning by transforming the occupational composition ratio and preventing occupational CO poisoning. ${ }^{39}$ In terms of age, all regions showed proportions of $\mathrm{CO}$ poisoning-induced deaths decreasing in the under-50s and increasing in the over-50s, which was consistent with global trends. The most pronounced EAPC observed was the decline in the under-5s in more than half of the geographical regions. However, the EAPC was positive in Eastern Sub-Saharan Africa, most pronounced in the under-5s, where this age group comprises $15.81 \%$ of the population. ${ }^{52}$ The overall EAPC is negative in Central Asia, while its most pronounced age-stratified EAPC is a positive value for the over-70s. Examples include Mongolia, Uzbekistan and Thailand, consistent with the increasing trend in this age group in areas with middle SDI scores. Projections of ageing in populations indicate that in $2050,80 \%$ of older people will be living in low-income and middle-income countries. $^{40}$

Although the GBD estimates fill a gap where actual data on disease burden are sparse or unavailable, several limitations should be noted. First, the accuracy and robustness of GBD estimates largely depend on the quality and quantity of data used in the modelling. For example, the misdiagnosis of $\mathrm{CO}$ poisoning as influenza, gastroenteritis or infantile colic ${ }^{2}{ }^{3}$ and the underreporting of CO poisoning, ${ }^{53}$ affect GBD data quality. Second, there may be an underestimation of individual CO poisoning aetiologies, such as coal stoves used for heating, shower system water heaters, or building or house fires, owing to a lack of relevant information. Consequently, these variables were not assessed in the current study. The quality and completeness of reporting issues may be more likely to occur in underdeveloped countries, which may account for unexpectedly low rates of mortality than found in developed countries where surveillance tools to support the accuracy of data may be more readily available.

In summary, $\mathrm{CO}$ poisoning remains a major global public health concern. ${ }^{14}$ Although we have achieved great success in its prevention and treatment across the world, high ASRs and EAPCs were observed in most low-SDI scoring countries and a few with middle-to-high scores. This indicates the necessity for laws mandating $\mathrm{CO}$ alarm installation and $\mathrm{CO}$ poisoning awareness campaigns (eg, media reports, community health fairs, free alarm distribution and educational materials). Moreover, workers training on $\mathrm{CO}$ poisoning and innovation and improvement in workplace technology could reduce occupational $\mathrm{CO}$ poisoning deaths. CO poisoning in the elderly is a global health concern that cannot be ignored. More attention should be paid to the elderly in middle-income countries using interventions, such as developing systems for providing long-term care that collaborates across sectors and levels of government. ${ }^{54}$

\section{Author affiliations}

${ }^{1}$ Pulmonary and Critical Care Medicine, Beijing Tian Tan Hospital, Capital Medical University, Fengtai-qu, Beijing, China

${ }^{2}$ Department of Chemical Poisoning Treatment, Department of Hematology, 5th Medical Center of Chinese PLA General Hospital, Fengtai-qu, Beijing, China ${ }^{3}$ Department of Intensive Care Medicine, Hainan Hospital of PLA General Hospital, Sanya, Hainan, China

Correction notice This article has been corrected since it was first published. Long Jianhai and sun Ya Wei are co-first authors, and Peng Xiaobo and Liu Jie are co-corresponding authors.

Acknowledgements We would like to thank the GBD database for the collection of carbon monoxide poisoning epidemiological data.

Contributors Study design: JLiu and XP. Data collection: YS, JZ. Data analysis: YS, JZ. Figures: JLong, YS. Manuscript writing: JLong, XP. Manuscript proofing: JLong, $X P$. All authors read and approved the manuscript.

Funding The authors have not declared a specific grant for this research from any funding agency in the public, commercial or not-for-profit sectors.

Map disclaimer The inclusion of any map (including the depiction of any boundaries therein), or of any geographic or locational reference, does not imply the expression of any opinion whatsoever on the part of BMJ concerning the legal status of any country, territory, jurisdiction or area or of its authorities. Any such expression remains solely that of the relevant source and is not endorsed by BMJ. Maps are provided without any warranty of any kind, either express or implied.

Competing interests None declared.

Patient consent for publication Not applicable.

Ethics approval Not applicable. Secondary-analysis based on GBD database did not involve personal information and privacy.

Provenance and peer review Not commissioned; externally peer reviewed.

Data availability statement Data are available in a public, open access repository.

Supplemental material This content has been supplied by the author(s). It has not been vetted by BMJ Publishing Group Limited (BMJ) and may not have been peer-reviewed. Any opinions or recommendations discussed are solely those of the author(s) and are not endorsed by BMJ. BMJ disclaims all liability and responsibility arising from any reliance placed on the content. Where the content includes any translated material, BMJ does not warrant the accuracy and reliability of the translations (including but not limited to local regulations, clinical guidelines, terminology, drug names and drug dosages), and is not responsible for any error and/or omissions arising from translation and adaptation or otherwise.

Open access This is an open access article distributed in accordance with the Creative Commons Attribution Non Commercial (CC BY-NC 4.0) license, which permits others to distribute, remix, adapt, build upon this work non-commercially, and license their derivative works on different terms, provided the original work is properly cited, appropriate credit is given, any changes made indicated, and the use is non-commercial. See: http://creativecommons.org/licenses/by-nc/4.0/.

ORCID iD

Xiaobo Peng http://orcid.org/0000-0003-0655-5296

\section{REFERENCES}

1 lqbal S, Clower JH, Hernandez SA, et al. A review of disasterrelated carbon monoxide poisoning: surveillance, epidemiology, and opportunities for prevention. Am J Public Health 2012;102:1957-63.

2 lqbal S, Law H-Z, Clower JH, et al. Hospital burden of unintentional carbon monoxide poisoning in the United States, 2007. Am J Emerg Med 2012;30:657-64.

3 Gozubuyuk AA, Dag H, Kacar A, et al. Epidemiology, pathophysiology, clinical evaluation, and treatment of carbon monoxide poisoning in child, infant, and fetus. North Clin Istanb 2017;4:100-7.

4 Barret L, Danel V, Faure J. Carbon monoxide poisoning, a diagnosis frequently overlooked. J Toxicol Clin Toxicol 1985;23:309-13.

5 Raub JA, Mathieu-Nolf M, Hampson NB, et al. Thom SR: Carbon monoxide poisoning-a public health perspective. Toxicology 2000;145:1-14.

6 Centers for Disease Control and Prevention (CDC). Nonfatal, unintentional, non--fire-related carbon monoxide exposures--United States, 2004-2006. MMWR Morb Mortal Wkly Rep 2008;57:896-9. 
7 Karapirli M, Kandemir E, Akyol S, et al. Forensic and clinical carbon monoxide (CO) poisonings in turkey: a detailed analysis. J Forensic Leg Med 2013;20:95-101.

8 LaSala G, McKeever R, Okaneku J, et al. The epidemiology and characteristics of carbon monoxide poisoning among recreational boaters. Clin Toxicol 2015;53:127-30.

9 Mendoza JA, Hampson NB. Epidemiology of severe carbon monoxide poisoning in children. Undersea Hyperb Med 2006;33:439-46.

10 Centers for Disease Control and Prevention (CDC). Notes from the field: carbon monoxide exposures reported to poison centers and related to hurricane Sandy - Northeastern United States, 2012. MMWR Morb Mortal Wkly Rep 2012;61:905.

11 Hosseininejad SM, Aminiahidashti H, Goli Khatir I, et al. Carbon monoxide poisoning in Iran during 1999-2016: a systematic review and meta-analysis. J Forensic Leg Med 2018;53:87-96.

12 Sircar K, Clower J, Shin MK, et al. Carbon monoxide poisoning deaths in the United States, 1999 to 2012. Am J Emerg Med 2015;33:1140-5.

13 Mott JA, Wolfe MI, Alverson CJ, et al. National vehicle emissions policies and practices and declining us carbon monoxide-related mortality. JAMA 2002;288:988-95.

14 Janík M, Ublová M, Kucerová Štepánka, et al. Carbon monoxiderelated fatalities: a 60-year single institution experience. J Forensic Leg Med 2017;48:23-9.

15 Kreitman N. The coal gas story. United Kingdom suicide rates, $1960-$ 71. Br J Prev Soc Med 1976;30:86-93.

16 Weaver LK, Deru K, Churchill S, et al. Carbon monoxide poisoning in Utah: 1996-2013. Undersea Hyperb Med 2016;43:747-58.

17 Ran T, Nurmagambetov T, Sircar K. Economic implications of unintentional carbon monoxide poisoning in the United States and the cost and benefit of $\mathrm{CO}$ detectors. Am J Emerg Med 2018;36:414-9.

18 Runyan CW, Johnson RM, Yang J, et al. Risk and protective factors for fires, burns, and carbon monoxide poisoning in U.S. households. Am J Prev Med 2005;28:102-8.

19 Division of Environmental Hazards and Health Effects. Health NCfE: prevention guidelines: you can prevent carbon monoxide exposure. in. edited by USA HHS, 2017. Available: https://www.cdc.gov/co/ guidelines.htm

20 Huang $\mathrm{C}-\mathrm{C}$, Ho $\mathrm{C}-\mathrm{H}$, Chen $\mathrm{Y}-\mathrm{C}$, et al. Effects of hyperbaric oxygen therapy on acute myocardial infarction following carbon monoxide poisoning. Cardiovasc Toxicol 2020;20:291-300.

21 Wang GS, Levitan R, Wiegand TJ, et al. Extracorporeal membrane oxygenation (ECMO) for severe toxicological exposures: review of the toxicology Investigators Consortium (toxic). J. Med. Toxicol. 2016;12:95-9.

22 Hampson NB. U.S. mortality due to carbon monoxide poisoning, 1999-2014. accidental and intentional deaths. Ann Am Thorac Soc 2016;13:1768-1774.

23 Fisher DS, Leonardi G, Flanagan RJ. Fatal unintentional non-firerelated carbon monoxide poisoning: England and Wales, 1979-2012. Clin Toxicol 2014;52:166-70.

24 Ghosh RE, Close R, McCann LJ, et al. Analysis of hospital admissions due to accidental non-fire-related carbon monoxide poisoning in England, between 2001 and 2010. J Public Health 2016;38:76-83.

25 Braubach M, Algoet A, Beaton M, et al. Mortality associated with exposure to carbon monoxide in who European member states. Indoor Air 2013;23:115-25.

26 Walker E, Hay A. Carbon monoxide poisoning. BMJ 1999;319:1082-3.

27 Institute for Health Metrics and Evaluation. Data from:Global burden of disease study 2017 (GBD 2017) data resources | GHDx. GBD online database, 2019. Available: http://ghdx.healthdata.org/gbd2017

28 GBD 2017 Disease and Injury Incidence and Prevalence Collaborators. Global, regional, and national incidence, prevalence, and years lived with disability for 354 diseases and injuries for 195 countries and territories, 1990-2017: a systematic analysis for the global burden of disease study 2017. Lancet 2018;392:1789-858.

29 Institute for Health Metrics and Evaluation. Data from: global burden of disease study 2017 (GBD 2017) socio-demographic index (SDI) 1950-2017. GBD online database, 2019. Available: http://ghdx. healthdata.org/sites/default/files/record-attached-files/IHME GBD 2017_SDI_1950_2017.zip
30 Global Burden of Disease Cancer Collaboration, Fitzmaurice C, Abate D, et al. Global, regional, and National cancer incidence, mortality, years of life lost, years lived with disability, and DisabilityAdjusted life-years for 29 cancer groups, 1990 to 2017: a systematic analysis for the global burden of disease study. JAMA Oncol 2019;5:1749-68.

31 Liu Z, Jiang $\mathrm{Y}$, Yuan $\mathrm{H}$, et al. The trends in incidence of primary liver cancer caused by specific etiologies: results from the global burden of disease study 2016 and implications for liver cancer prevention. $J$ Hepatol 2019;70:674-83.

32 UNITED NATIONS DEVELOPMENT PROGRAMME. Data from: human development index (HDI). human development reports, 2021. Available: http://hdr.undp.org/en/indicators/137506\#

33 Hankey BF, Ries LA, Kosary CL, et al. Partitioning linear trends in age-adjusted rates. Cancer Causes Control 2000;11:31-5.

34 Hung G-Y, Horng J-L, Yen H-J, et al. Changing incidence patterns of hepatocellular carcinoma among age groups in Taiwan. $J$ Hepatol 2015;63:1390-6.

35 Gao S, Yang W-S, Bray F, et al. Declining rates of hepatocellular carcinoma in urban Shanghai: incidence trends in 1976-2005. Eur J Epidemiol 2012;27:39-46.

36 Liu Z, Suo C, Mao X, et al. Global incidence trends in primary liver cancer by age at diagnosis, sex, region, and etiology, 1990-2017. Cancer 2020;126:2267-78.

37 Gao S, Yang W-S, Bray F, et al. Declining rates of hepatocellular carcinoma in urban Shanghai: incidence trends in 1976-2005. Eur J Epidemiol 2012;27:39-46.

38 Mattiuzzi C, Lippi G. Worldwide epidemiology of carbon monoxide poisoning. Hum Exp Toxicol 2020;39:387-92.

39 Henn SA, Bell JL, Sussell AL, et al. Occupational carbon monoxide fatalities in the US from unintentional non-fire related exposures, 1992-2008. Am J Ind Med 2013;56:1280-9.

40 World Health Organization. Organization WH: ageing and health. in: World Health Organization: newsroom, 2018. Available: https://www. who.int/news-room/fact-sheets/detail/ageing-and-health

41 Omaye ST. Metabolic modulation of carbon monoxide toxicity. Toxicology 2002;180:139-50.

42 Centers for Disease Control and Prevention (CDC). Carbon monoxide--related deaths--United States, 1999-2004. MMWR Morb Mortal Wkly Rep 2007;56:1309-12.

43 Li F, Chan HCO, Liu S, et al. Carbon monoxide poisoning as a cause of death in Wuhan, China: a retrospective sixyear epidemiological study (2009-2014). Forensic Sci Int 2015;253:112-8.

44 Khadem-Rezaiyan M, Afshari R. Carbon monoxide poisoning in northeast of Iran. J Forensic Leg Med 2016;41:1-4.

45 GBD 2016 Healthcare Access and Quality Collaborators. Measuring performance on the healthcare access and quality index for 195 countries and territories and selected subnational locations: a systematic analysis from the global burden of disease study 2016 . Lancet 2018;391:2236-71.

46 Harduar-Morano L, Watkins S. Review of unintentional non-firerelated carbon monoxide poisoning morbidity and mortality in Florida, 1999-2007. Public Health Rep 2011;126:240-50.

47 Uysal C, Celik S, Duzgun Altuntas A, et al. Carbon monoxiderelated deaths in Ankara between 2001 and 2011. Inhal Toxico 2013;25:102-6.

48 Tuusov J, Vals K, Tõnisson M, et al. Fatal poisoning in Estonia 2000-2009. trends in illegal drug-related deaths. J Forensic Leg Med 2013;20:51-6.

49 labal S, Clower JH, Saha S, et al. Residential carbon monoxide alarm prevalence and ordinance awareness. J Public Health Manag Pract 2012;18:272-8.

50 Friedlander AM. Marine conservation in Oceania: past, present, and future. Mar Pollut Bull 2018;135:139-49.

51 Peterson RR. Over the Caribbean top: community well-being and Over-Tourism in small island tourism economies. Int $\mathrm{J}$ Community Wellbeing 2021:1-38.

52 Nations U: Department of Economic and Social Affairs, Population Division. World population prospects 2019, online edition, Rev. 1, 2019. Available: https://population.un.org/wpp/Download/Standard/ Population/

53 Chou C-H, Lai C-H, Liou S-H, et al. Carbon monoxide: an old poison with a new way of poisoning. J Formos Med Assoc 2012;111:452-5.

54 Organization WH. World report on ageing and health, 2015. Available: https://apps.who.int/iris/handle/10665/186463 